\title{
Performance of a Low Cost Interdigitated Flow Design on a 1 kW Class All Vanadium Mixed Acid Redox Flow Battery
}

\author{
David Reed, Edwin Thomsen, Bin Li*, Wei Wang, Zimin Nie, Brian Koeppel and Vincent \\ Sprenkle \\ Pacific Northwest National Laboratory,
}

902 Battelle Boulevard, P.O. Box 999, Richland, WA 99352, USA

\begin{abstract}
Three flow designs were operated in a 3 -cell $1 \mathrm{~kW}$ class all vanadium mixed acid redox flow battery. The influence of electrode surface area and flow rate on the coulombic, voltage, and energy efficiency and the pressure drop in the flow circuit will be discussed and correlated to the flow design. Material cost associated with each flow design will also be discussed.
\end{abstract}

Key words: Vanadium redox flow battery, flow design, electrical performance, material cost

* $\quad$ Corresponding author, Tel.: 1-509-375-2782; fax: 1-509-375-2186

902 Battelle Blvd., Richland, WA 99352, USA

E-mail address: Bin.li@pnnl.gov

(C) 2015. This manuscript version is made available under the Elsevier user license http://www.elsevier.com/open-access/userlicense/1.0/ 


\section{Introduction}

Combining renewable energy with the current electrical grid has large scale energy storage devices play a leading role in bridging the gap between new technologies and supporting a clean and efficient electrical grid system [1]. Redox flow batteries (RFBs) are capable of storing large quantities of electricity (multi MWs) with a simple design [1,2] and are thus seen as one of the most promising energy storage technologies [3,4]. Of the available types of RFBs, the all vanadium system is one of the most studied and most promising because it lacks some inherit problems associated with other types such as minor cross contamination. Other types of RFBs have different redox couple species used in each half cell and eventually creates cross contamination due to a lack of an ideal membrane.

A RFB is a type of reversible energy storage system that is able to store electrical energy in the form of chemical energy, and convert that energy into electricity. Typically, the RFB consists of two electrolyte reservoirs from which the electrolyte is circulated through the flow circuit via pumps. Individual cells are then connected to one another in either series or parallel to form a stack. One advantage of a RFB is that the power and energy specifications can be scaled independently. The amount of energy stored is proportional to the amount of active species in the electrolyte solution via the storage reservoir volume and electrolyte concentration. The power on the other hand is directly proportional to the reactor or stack size.

The first redox flow battery was developed nearly 40 years ago in 1975 by the National Aeronautics and Space Administration (NASA) and was based on the $\mathrm{Fe}^{2+/ 3+}-\mathrm{Cr}^{2+/ 3+}$ system [5]. This early redox flow battery suffered from severe cross contamination and hydrogen evolution 
at the anode side during operation and lead to the development of two additional redox flow batteries, namely GEN $2 \mathrm{Fe} / \mathrm{Cr}$ and the all vanadium flow battery (VRB) [6,7].

The GEN $2 \mathrm{Fe} / \mathrm{Cr}$ and the VRB have been instrumental in advancing the redox flow battery technology with demonstration systems in the multi-MWh but still do not meet all of the cost and performance targets needed to fully penetrate the market. The VRB has made some significant advanced in past decades [8] but until recently had limited vanadium ion solubility and stability over a narrower temperature range. Recent work at the Pacific Norwest National Laboratory (PNNL) has developed a mixed acid system based on a chloride-sulfate acid system. The mixed acid system has significantly improved the active species concentration and increased the operation temperature range compared to the sulfate acid based system [9-12].

For VRBs to be used in more application and penetrate a broader market, the performance needs to be continually improved and the cost reduced. This paper will address performance and cost associated with an all vanadium mixed acid $1 \mathrm{~kW}$ class stack with different flow design aimed at reducing the pressure drop in the circuit and associated pumping losses and improving the overall system efficiency.

\section{Experimental}

VOSO4 $\cdot \mathrm{xH}_{2} \mathrm{O}$ (Noah Technologies, San Antonia, TX, 99.5\%, x = 2.0 2.3), HCl (SigmaAldrich, 37\%), and $\mathrm{H}_{2} \mathrm{SO}_{4}$ (Sigma-Aldrich, 95.8\%) were used as the starting sources for the mixed acid electrolyte, $2 \mathrm{M}$ VOSO4 + 5M HCl.

Three cell stacks were used in all experiments to fabricate a $1 \mathrm{~kW}$ class stack. Aluminum end plates, bolts, and tin coated copper current collector plates were used for structural support and electrical connection to the stack, respectively [11]. The integrated design combines the 
anode and cathode flow frames, porous graphite felt sheets as the electrodes (SGL GFD4.6 or GFD 2.5), and a solid graphite plate as the bipolar plate (SGL TF6 or PPG86) into a single component used as the basic building block. The graphite felt sheets used as the electrodes were thermally heat treated in air at $400^{\circ} \mathrm{C}$ for 6 hours and them compressed by $\sim 15-20 \%$ during assembly. Nafion ${ }^{\circledR}$ NR-212 membranes were used in all designs and soaked in deionized water for 14 hours prior to assembly. Active area of cells was $780 \mathrm{~cm}^{2}$ and overall stack dimensions are $31(\mathrm{w}) \times 44(\mathrm{~h}) \times 40(\mathrm{l}) \mathrm{cm}$.

Three different flow designs were fabricated and tested as a function of current density and flow rate. A schematic cross section and top view of the three designs is shown in Figure 1 a-c. In all cases, the design was symmetrical for both the anode and cathode. The first flow through design (FTD) is shown in Figure 1a and utilizes SGL TF6 graphite sheet as the bipolar plate and SGL GFD4.6 carbon felt with the thickness of $4.6 \mathrm{~mm}$ as the electrode. Electrolyte flow for the flow through design is from left to right through the carbon felt. The second design, Figure $1 \mathrm{~b}$, is an interdigitated flow design which uses SGL PPG 86, a composite made from graphite and polypropylene, as the bipolar plate and SGL GFD2.5 carbon felt with the thickness of $2.5 \mathrm{~mm}$ as the electrode. Flow channels were machined directly into the bipolar plate and the flow direction is depicted in Figure 1b. A second interdigitated flow design, Figure 1c, was also fabricated and also used the SGL TF6 graphite sheet as the bipolar plate but uses two sheet of the SGL GFD2.5 carbon felt as the electrode. The flow channels for the third design (IDD2) was cut or scribed directly into the carbon felt sheet adjacent to the bipolar plate. The second carbon felt sheet was placed between the scribed carbon felt and the Nafion membrane. The same flow pattern dimensions were used for both interdigitated flow designs (IDD1 and IDD2) and the flow direction is shown in Figure 1. 
The interdigitated flow field concept features parallel oriented channels, adjacent to the felt electrode, that extend from the inflow and outflow reservoirs of the cell as shown in Figures $1 \mathrm{~b}$ and $\mathrm{c}$. The tapered flow channels can better control the pressure gradient along the channel length at lower flow rates to improve velocity uniformity in the porous felt layer.

An in house designed test system was used to measure stack performance, Figure 2 [11, 13]. The test system includes two electrolyte reservoir tanks, two centrifugal pumps (Finnish Thompson, DB4V-T-M613), two flow meters (Omega FMG83 Magmeters), pressure sensors (Measurement Specialities MSP-300-100-P-1-N-1) and temperature sensors, a transfer pump, valves and a 3 cell stack. The volume of the anolyte and catholyte were approximately $6 \mathrm{~L}$ in the high density polyethylene storage tanks. Each tank contains a port for the supply and return of the electrolyte and additional ports for pressure and temperature sensors, a transfer line, and a nitrogen purge line. Type $\mathrm{N}$ thermocouples (1/8”) coated with Teflon were inserted inside each tank to measure the electrolyte temperature during operation. The anode and cathode tanks are connected pneumatically by a $1 / 4 "$ tube to avoid mechanical pressure variation attributed to the electrolyte volume change as a result of ionic or water transport across the Nafion ${ }^{\circledR}$ membrane during operation. Pressure drop in the cathode and anode flow circuits was measured using a pressure transducer placed between the pump and the stack inlet, respectively.

Electrochemical performance of the 3 cell stacks was evaluated using an Arbin Instruments, BT-2000, battery tester. The Arbin battery tester was used to monitor cell voltages, flow and temperature measurements, and pressure drop in the flow circuits. To prevent oxidation of active species with air, the system was purged with nitrogen and sealed before evaluation. The redox flow battery was cycled between 1.75 and $1.1 \mathrm{~V} / \mathrm{cell}$ at $160 \mathrm{~mA} / \mathrm{cm}^{2}$, and between 1.80 and $1.05 \mathrm{~V} /$ cell at $240 \mathrm{~mA} / \mathrm{cm}^{2}$. The voltage range differs to compensate for the 
different ohmic losses and ensure that the state of charge (SOC) range is held nearly constant between 15 and $85 \%[11,13]$. Prior to each test, the anolyte and catholyte were totally remixed and charged to ensure identical initial test conditions. Listed in Table 1 are the specifications of the $1 \mathrm{~kW}$ stacks used in this study.

The coulombic, voltage, and energy efficiency of the stack was measured for the three designs as a function of current density $\left(160 \mathrm{~mA} / \mathrm{cm}^{2}\right.$ and $\left.240 \mathrm{~mA} / \mathrm{cm}^{2}\right)$ and flow rate $(400,800$, and $1200 \mathrm{cc} / \mathrm{min} / \mathrm{cell})$. The coulombic and energy efficiencies are defined as:

$$
\begin{aligned}
& \text { Stack coulomb efficiency (CE) }=\frac{\int i_{d} d t}{\int i_{c} d t} \\
& \text { Stack energy efficiency (EE) }=\frac{\int p_{d} d t}{\int p_{c} d t}=\frac{\int V_{d} i_{d} d t}{\int V_{c} i_{c} d t}
\end{aligned}
$$

where $i$ denotes current, $p$ is power, $V$ is voltage, and $c$, and $d$ denote charging and discharging, respectively.

\section{Results and Discussion}

As described earlier, for VRBs to be used in more applications and penetrate a broader market, the performance needs to be continually improved and the cost reduced. One way to address this issue is to operate at higher current densities while maintaining good energy efficiency. In general, the current density dictates the overall power of the system and tends to reduce the footprint of the stack but limits the performance due to increased ohmic and polarizations losses. It is the aim of this study to increase the current density while maintaining good electrical performance. In a previous publication the ohmic loses attributed from the Nafion membrane was reduced to improved stack energy efficiency [13]. In the present study 
the flow rate will be investigated via different flow designs to further improve the overall system efficiency. In future publications, the influence of temperature, flow rate, electrode microstructure, and flow design will also be investigated to maintain and/or improve the stack energy efficiency with increasing current density.

The three flow designs depicted in Figure 1 and specifications given in Table 1 utilize similar carbon materials for the electrodes except for the felt thickness. Electrolyte flows from the inlet ports on the left through the carbon felt and exits the outlet ports on the right as shown in Figure 1 for the flow through design. For the interdigitated designs, the electrolyte also flows through the inlet ports, through the channels in the carbon felt or bipolar plate, and then through the carbon felt in a direction perpendicular to the ports and channels. The electrolyte then flows through the exit channels in the carbon felt and exits through the outlet ports, Figure 1. The SGL GFD 4.6 and GFD 2.5 are similar material with similar characteristics (morphology, pore size, surface area, etc.) except for the corresponding thickness. Figure 3 is a SEM micrograph of the SGL GFD 4.6 material used as the electrode material in this study. This material provides good electrical conductivity ( 2-3 S/cm) while providing significant porosity (> 90\%) to allow sufficient flow of the electrolyte through the cell during operation [14].

The flow through design (FTD) and the second interdigitated design (IDD 2) have a similar electrode felt thickness, $4.6 \mathrm{~mm}$ versus $5.0 \mathrm{~mm}(2.5 \mathrm{~mm}+2.5 \mathrm{~mm})$, respectively. The first interdigitated design (IDD1), however, has an electrode thickness of only $2.5 \mathrm{~mm}$. Therefore, it would be expected that the FTD and the IDD 2 would also have the highest surface area available in the electrodes to act as sites for the electrochemical reaction, Table 2. IDD 2 has less surface area than the FTD because of the missing electrode material that has been 
removed by laser machining for flow channels in the interdigitated design. The first interdigitated design (IDD 1) has the lowest electrode surface area of the three designs studied.

\subsection{Lowest Flow Rate Condition - (400 cc/min/cell)}

The voltage efficiency for the three flow designs at a flow rate of $400 \mathrm{cc} / \mathrm{min} / \mathrm{cell}$ as a function of current density $\left(160 \mathrm{~mA} / \mathrm{cm}^{2}\right.$ and $\left.240 \mathrm{~mA} / \mathrm{cm}^{2}\right)$ is shown in Figure 4 (a). Electrolyte temperature during operation was monitored in the storage tanks and found to be $\sim 35$ to $40^{\circ} \mathrm{C}$ and $\sim 45^{\circ} \mathrm{C}$ when the stacks were operated at $160 \mathrm{~mA} / \mathrm{cm}^{2}$ and $240 \mathrm{~mA} / \mathrm{cm}^{2}$, respectively. As the current density is increased the performance is limited due to increased ohmic and polarization losses. Although there is likely an ohmic contribution at each current density, the difference between the flow designs at each current density is, however, most likely polarization losses associated with the electrochemical reactions. The flow design with the highest voltage efficiency also had the highest electrode surface area and vice versa. The coulombic efficiency is similar in all cases $(\sim 97 \%)$, therefore the voltage efficiency depicted in Figure 4 (a) is directly correlated to the stack energy efficiency for the same given conditions, Figure 4 (b). Figure 4 (c) shows the correlation between the electrode surface area and the voltage efficiency of the electrode for the three flow designs as a function of current density. As the surface area is increased, there are more available sites to drive the electrochemical reaction and thereby decrease the polarization losses. As expected, the voltage efficiency is not linear over the range of surfaces areas studied but appears to have a larger influence at larger surface areas and higher current densities. Other factors that could influence the electrode kinetics such as electrolyte velocity, etc. could also be contributing to the performance of the electrodes. Fabricating cells 
with even higher surface area electrodes will be examined as a function of current density and flow rate and will be reported in subsequent publications.

The discharge capacity $(\mathrm{Ah} / \mathrm{L})$ for the three flow designs as a function of current density at $400 \mathrm{cc} / \mathrm{min} / \mathrm{cell}$ is shown in Figure 4 (d). As expected, the discharge capacity was the greatest for the flow through design and the smallest for the interdigitated design 1 at the lowest flow rate, $400 \mathrm{cc} / \mathrm{min} / \mathrm{cell}$.

The pressure drop during operation was monitored by placing pressure transducers between the pumps and the stack inlet in both the anode and cathode flow circuit. The maximum pressure drop for the three flow designs at $400 \mathrm{cc} / \mathrm{min} / \mathrm{cell}$ and at current densities of 160 $\mathrm{mA} / \mathrm{cm}^{2}$ and $240 \mathrm{~mA} / \mathrm{cm}^{2}$ is shown in Figure 5. The pressure drop for the two interdigitated designs is approximately three times lower than the pressure drop of the standard flow through design at $400 \mathrm{c} / \mathrm{min} / \mathrm{cell}$. The pressure drop was limited to approximately $10 \mathrm{psi}$ in this study to minimize pump losses. The pressure drop at the highest current density is lower due to the increased electrolyte operating temperature which decreases the electrolyte viscosity. This effect is less pronounced with the interdigitated designs because the pressure drops are already quite low at the lowest current density studied.

\subsection{Higher Flow Rate Conditions - (800-1200 cc/min/cell)}

The electrolyte flow rate is another parameter that can influence the performance of the flow battery stack. Higher flow rates decrease mass transport losses [15] especially at high current densities which can improve stack performance. A balance between the current density of operation and the electrolyte flow rate is important to maximize overall system efficiency. Up to this point in this study the flow rate has been held constant, $400 \mathrm{cc} / \mathrm{min} / \mathrm{cell}$, to directly 
compare the performance of the flow designs. However, the interdigitated designs were fabricated to operate at higher flow rates without substantially increasing the pressure drop in the circuit. The remainder of this study will focus on increasing the flow rate of the two interdigitated designs while maintaining a pressure drop at 10 psi or below. The flow through design had reached the maximum pressure drop at $400 \mathrm{cc} / \mathrm{min} / \mathrm{cell}$ and will therefore be used as the baseline for this flow design, Figure 5.

The voltage efficiency for the two interdigitated designs at 400, 800, and 1200 $\mathrm{cc} / \mathrm{min} / \mathrm{cell}$ at $160 \mathrm{~mA} / \mathrm{cm}^{2}$ and $240 \mathrm{~mA} / \mathrm{cm}^{2}$ along with the flow through design at 400 cc/min/cell are shown in Figure 6 (a) and (b). The voltage efficiency for the interdigitated designs has increased with increasing flow rate due to higher mass transport losses at lower flow rates. The same behavior is observed for the two interdigitated designs at the lowest flow rate: the design with the highest surface area electrode corresponds to the highest voltage efficiency at a given flow rate. Again, the coulombic efficiency is similar in all cases for the interdigitated designs at higher flow rates, therefore, the differences in the voltage efficiencies in Figure 6 (a) and (b) are directly correlated to the differences in the stack energy efficiencies depicted in Figure 6 (c) and (d). The stack energy efficiency has been improved and is greater than the flow through design in the highest flow rate case. Several variables investigated in this study are important and need to be balanced when determining the overall system efficiency including: high surface area electrodes, an interdigitated design to lower the pressure drop and pumping losses and higher flow rates.

Shown in Figure 7 (a) and (b) are voltage efficiency of the two interdigitated designs as a function of flow rate and current density. The dependencies in all cases are nearly linear over the 
flow rate studied. However, one would expect that at higher flow rates the voltage efficiency would plateau due to mass transport losses or flooding of the electrolyte at the electrode.

The discharge capacity (Ah/L) for the two interdigitated designs at 400, 800, and 1200 cc/min/cell at $160 \mathrm{~mA} / \mathrm{cm}^{2}$ and $240 \mathrm{~mA} / \mathrm{cm}^{2}$ along with the flow through design at 400 cc/min/cell are shown in Figure 7 (c) and (d). The discharge capacity was shown to be the greatest for the flow through design at the lowest flow rate, but the interdigitated designs exceed those values at the highest current density studied.

The pressure drop was also monitored for the interdigitated designs at the higher flow rates at $160 \mathrm{~mA} / \mathrm{cm}^{2}$ and $240 \mathrm{~mA} / \mathrm{cm}^{2}$ as shown in Figure 7 (e) and (f) along with the standard flow through design at the lowest flow rate. The interdigitated designs appear to give a similar pressure response and allow the flow rates to be tripled in the new designs. Again, the pressure drop at the highest current density is lower due to the increased electrolyte operating temperature which decreases the electrolyte viscosity as shown in Figure 7 (e) and (f).

Lastly, the stack material cost associated with each flow design was calculated and the results are shown in Figure 8. The standard flow through design had the lowest cost; this cost was normalized for comparison to the other designs. The second interdigitated design (IDD 2) was slightly higher in material cost attributed to the cost of two carbon felt sheets at $2.5 \mathrm{~mm}$ thick rather than one sheet at $4.6 \mathrm{~mm}$ thick (FTD). The first interdigitated design (IDD 1), however, is on the order of 2.5-3 times the cost of the flow through design. The primary material cost in IDD1 comes from the graphite/polypropylene sheets (SGL PPG 86). This cost does not include machining costs which in reality would further increase the cost of IDD 1. In general, the cost of the second interdigitated design (IDD 2) utilizing channels cut into the carbon felt electrode would slightly increase the cost but enables the flow rate to be significantly increased ( 
up to $3 \mathrm{X}$ ) with the same pressure drop and typically improved performance. All parameters must be examined such as pumping losses, etc. when determining overall system efficiency. But the above interdigitated designs do give the designer extra options to improve system efficiency by allowing for higher flow rates with minimal pressure drops while achieving a high performance. For the present conditions and interdigitated flow designs studied (IDD 1 and IDD 2), the second design (IDD2) fabricated with all carbon felt appears to be the design of choice because if gives similar performance results but is substantially lower in cost to IDD 1. Future studies, however, will further optimize these designs as the current density is increased and higher performance electrodes are investigated.

\section{Conclusions}

Three different flow designs were operated in a 3 cell $1 \mathrm{~kW}$ class all vanadium mixed acid redox flow battery to determine the influence of properties on the electrolyte flow rate. Limiting the pressure drop to $<10$ psi in the flow circuits, the standard flow through design had the highest stack energy efficiency compared to the two interdigitated designs at the lowest flow rate of $400 \mathrm{cc} / \mathrm{min} / \mathrm{cell}$. The available surface area of the carbon felt electrode was found to be directly correlated to the stack performance at the lowest flow rate $(400 \mathrm{cc} / \mathrm{min} / \mathrm{cell})$ and independent of current density. As the flow rate was increased up to $1200 \mathrm{cc} / \mathrm{min} / \mathrm{cell}$ (while maintaining a pressure drop below $10 \mathrm{psi}$ ), the stack energy efficiency of the interdigitated designs had a stack energy efficiency greater than the standard flow through design. The second interdigitated design (IDD 2) constructed of all carbon felt would be the design of choice for the flow rates and current densities studied because it had similar if not better stack performance at higher flow rates at a comparable cost to the standard flow design. This interdigitated design 
(IDD 2) would give the stack designer flexibility in terms of operating flow rate and current density to optimize overall system performance at a minimal cost.

\section{Acknowledgements}

This work is supported by the Office Electricity Delivery \& Energy Reliability's storage

program. PNNL is a multiprogram laboratory operated by Battelle Memorial Institute for the Department of Energy under Contract DE_ACS05-76RL01830.

\section{References}

[1] Z. Yang, J. Zhang, M.C.W. Kintner-Meyer, X. Lu, D. Choi, J.P. Lemmon, J. Liu, Chemical Reviews 111 (2011) 3577.

[2] Z. Yang, J.Liu, S.Baskaran, C.H. Imhoff, J.D. Holladay, JOM, 62, (2010) 14.

[3] W. Wang, Q. Luo, B. Li, X. Wei, L. Li, Z. Yang, Advanced Functional Materials (2012).

[4] M. Skyllas-Kazacos, M.H. Chakrabarti, S.A. Hajimolana, F.S. Mjalli, M. Saleem. J. Electrochem Soc. 158 (2011) R55.

[5] L.H. Thaller, Electrically Rechargeable Redox Flow Cells, NASA TM X-71540, National Aeronautics and Space Administration, 1974.

[6] A. Parasuraman, T.M. Lim, C. Menictas, M. Skyllas-Kazacos, Electrochimica Acta, 101 (2013) 27-40.

[7] M. Skyllas-Kazacos, F. Grossmith, J. Electrochem. Soc. 134 (1987) 2950-2953.

[8] S. Eckroad, Technical Report, EPRI-1014836, Electric Power Research Institute, Palo Alto, CA, USA, 2007.

[9] W. Wang, S. Kim, B. Chen, Z. Nie, J. Zhang, G. Xia, L. Li, Z. Yang, Energy and Environmental Science 4 (2011) 4068. 
[10] W. Wang, Z. Nie, B. Chen, F. Chen, Q. Luo, X. Wei, G. Xia, M. Skyllas-Kazacos, L. Li, Z. Yang, Advanced Energy Materials 2 (2012) 487.

[11] S. Kim, E. Thomsen, G. Xia, Z. Nie, J. Bao, K. Recknagle, W. Wang, V. Viswanathan, Q. Luo, X. Wei, A. Crawford, G. Coffey, G. Maupin and V. Sprenkle, J. Power Sources 237 (2013) 300-309.

[12] B. Li, L. Lu, W. Wang, Z. Nie. B. Chen, X. Wei, Q. Luo, Z. Yang, V. Sprenkle, J. Power Sources 229 (2013) 1-5.

[13] D. Reed, E. Thomsen, W. Wang, Z. Nie, B. Li, X. Wei, B. Koeppel, V. Sprenkle, J. Power Sources 285 (2015) 425-430.

[14] SGL website, http://www.sglgroup.com/cms/_common/downloads/products/productgroups/gs/brochures/Specialty_Graphites_for_Energy_Storage_e.pdf

[15] X. Ma, H. Zhang, C. Sun, Y. Zou and T. Zhang, J. Power Sources, 2012, 203, 153. 


\section{Figure Captions:}

Figure 1 Top and cross sectional view of the three flow designs a). flow through design (FTD), b). interdigitated design 1 (IDD 1), and c). interdigitated design 2 (IDD 2).

Figure 2. $1 \mathrm{~kW}$ vanadium redox flow battery testing system

Figure 3. SEM micrograph of the SGL GFD 4.6 material used as the electrode a). top view and $b)$. cross sectional view.

Figure 4. Voltage efficiency (a), stack energy efficiency (b), voltage efficiency versus surface area (c) and discharge capacity $(\mathrm{Ah} / \mathrm{L})(\mathrm{d})$ for the three flow designs at 160 and $240 \mathrm{~mA} / \mathrm{cm}^{2}$ and a flow rate of $400 \mathrm{cc} / \mathrm{min} / \mathrm{cell}$.

Figure5. Maximum pressure drop (psi) for the three flow designs at 160 and $240 \mathrm{~mA} / \mathrm{cm}^{2}$ and a flow rate of $400 \mathrm{cc} / \mathrm{min} / \mathrm{cell}$.

Figure 6. Voltage Efficiency for the three flow designs at various flow rates at a). 160 $\mathrm{mA} / \mathrm{cm}^{2}$ and b). $240 \mathrm{~mA} / \mathrm{cm}^{2}$; stack energy efficiency for the three flow designs at various flow rates at c). $160 \mathrm{~mA} / \mathrm{cm}^{2}$ and d). $240 \mathrm{~mA} / \mathrm{cm}^{2}$.

Figure 7. Voltage Efficiency for the two interdigitated flow designs as a function of flow rate at a). $160 \mathrm{~mA} / \mathrm{cm}^{2}$ and b). $240 \mathrm{~mA} / \mathrm{cm}^{2}$; discharge capacity (Ah/L) for the three flow designs as a function of flow rate at c). $160 \mathrm{~mA} / \mathrm{cm}^{2}$ and d). 240 $\mathrm{mA} / \mathrm{cm}^{2}$; pressure drop for the three flow designs as a function of flow rate at e). $160 \mathrm{~mA} / \mathrm{cm}^{2}$ andf). $240 \mathrm{~mA} / \mathrm{cm}^{2}$.

Figure 8. Normalized material costs (\%) for the three flow designs. 
Table 1: Specification of $1 \mathrm{~kW}$ class stack

\begin{tabular}{|c|c|c|}
\hline Dimensions $(\mathrm{cm})$ & & $31(\mathrm{~W}) \times 44(\mathrm{H}) \times 40(\mathrm{~L})$ \\
\hline Active area $\left(\mathrm{cm}^{2}\right)$ & & 780 \\
\hline Number of cells & & 3 \\
\hline $\begin{array}{l}\text { Electrode } \\
\text { Bipolar Plate }\end{array}$ & (FTD) & $\begin{array}{l}\text { Graphite felt (SGL GFD4.6) } \\
\text { SIGRACET® expanded graphite (TF6) }\end{array}$ \\
\hline $\begin{array}{l}\text { Electrode } \\
\text { Bipolar Plate }\end{array}$ & (IDD 1) & $\begin{array}{l}\text { Graphite felt (SGL GFD2.5) } \\
\text { SGL PPG } 86\end{array}$ \\
\hline $\begin{array}{l}\text { Electrode } \\
\text { Bipolar Plate }\end{array}$ & (IDD 2) & $\begin{array}{l}\text { Graphite felt (SGL GFD2.5 (x2)) } \\
\text { SIGRACET }{ }^{\circledR} \text { expanded graphite (TF6) }\end{array}$ \\
\hline Flow frame & & PVC (polyvinyl chloride) \\
\hline Membrane & & Nafion ${ }^{\circledR}$ NR-212 \\
\hline End plate & & Aluminum \\
\hline Power at $160 \mathrm{~mA} / \mathrm{cm}^{2}$ & & $\sim 0.50 \mathrm{~kW}$ \\
\hline Power at $240 \mathrm{~mA} / \mathrm{cm}^{2}$ & & $\sim 0.75 \mathrm{~kW}$ \\
\hline
\end{tabular}


Table 2: Surface area calculations for the three flow designs.

\begin{tabular}{|c|c|c|c|c|c|}
\hline $\begin{array}{c}\text { Flow } \\
\text { Design }\end{array}$ & $\begin{array}{l}\text { Electrode } \\
\text { Material }\end{array}$ & $\begin{array}{l}\text { Weight of } \\
\text { Electrode } \\
\text { (g) }\end{array}$ & $\begin{array}{l}\text { BET Surface } \\
\text { Area }\left(\mathrm{m}^{2} / \mathrm{g}\right) \\
\left(400^{\circ} \mathrm{C} \text { in }\right. \\
\text { air })\end{array}$ & $\begin{array}{c}\text { Electrode } \\
\text { Surface Area } \\
\left(\mathrm{m}^{2}\right)\end{array}$ & $\begin{array}{l}\text { Total Electrode } \\
\text { Surface Area } \\
\left(\mathrm{m}^{2}\right) \\
\quad(3 \text { cells })\end{array}$ \\
\hline FTD & GFD 4.6 & 31.9 & 0.5 & 16 & 96 \\
\hline IDD 1 & GFD 2.5 & 17.34 & 0.5 & 8.7 & 52.2 \\
\hline IDD 2 & GFD $2.5+$ GFD $2.5^{*}$ & 30.3 & 0.5 & 15.2 & 91.2 \\
\hline
\end{tabular}

* This GFD 2.5 was laser machined 


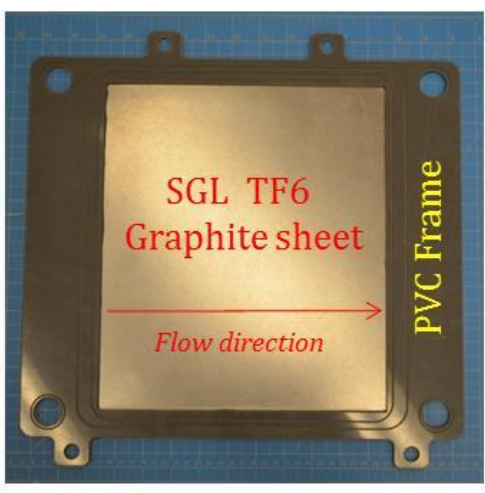

(FTD)

\begin{tabular}{c}
\hline Bipolar Plate \\
\hline Carbon Felt Electrode \\
\hline Membrane \\
\hline
\end{tabular}

a.

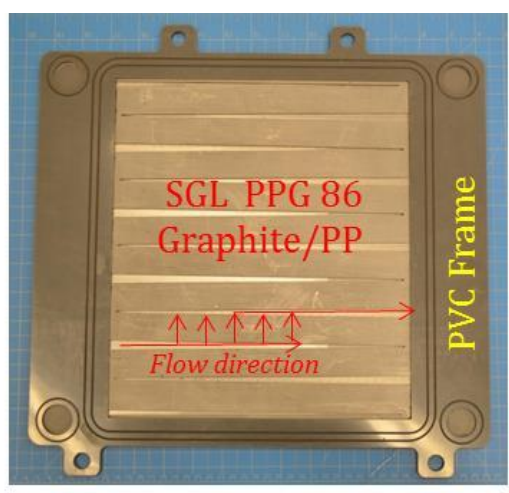

(IDD 1)

\begin{tabular}{|c|c|c|}
\hline \multicolumn{3}{|c|}{ Bipolar Plate } \\
\hline $\begin{array}{l}\text { Inlet } \\
\text { Channel }\end{array}$ & (Graphite/PP) & $\begin{array}{l}\text { Outlet } \\
\text { Channel }\end{array}$ \\
\hline \multicolumn{3}{|c|}{ Carbon Felt Electrode } \\
\hline & Membrane & \\
\hline
\end{tabular}

b.

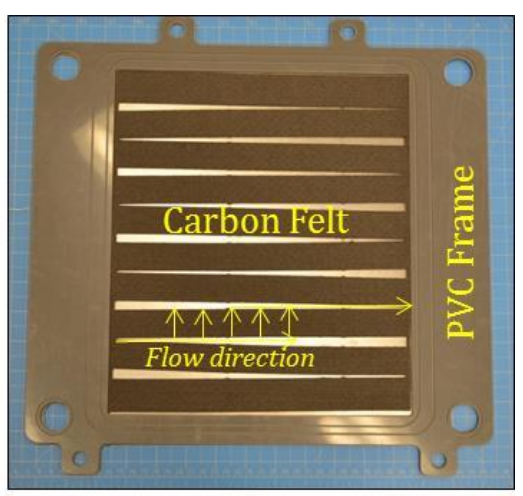

(IDD 2)

\begin{tabular}{|c|c|c|}
\hline \multicolumn{3}{|c|}{ Bipolar Plate } \\
\hline $\begin{array}{c}\text { Inlet } \\
\text { Channel }\end{array}$ & Carbon Felt Electrode & $\begin{array}{c}\text { Outlet } \\
\text { Channel }\end{array}$ \\
\hline \multicolumn{3}{|c|}{ Carbon Felt Electrode } \\
Membrane
\end{tabular}

c.

Figure 1 


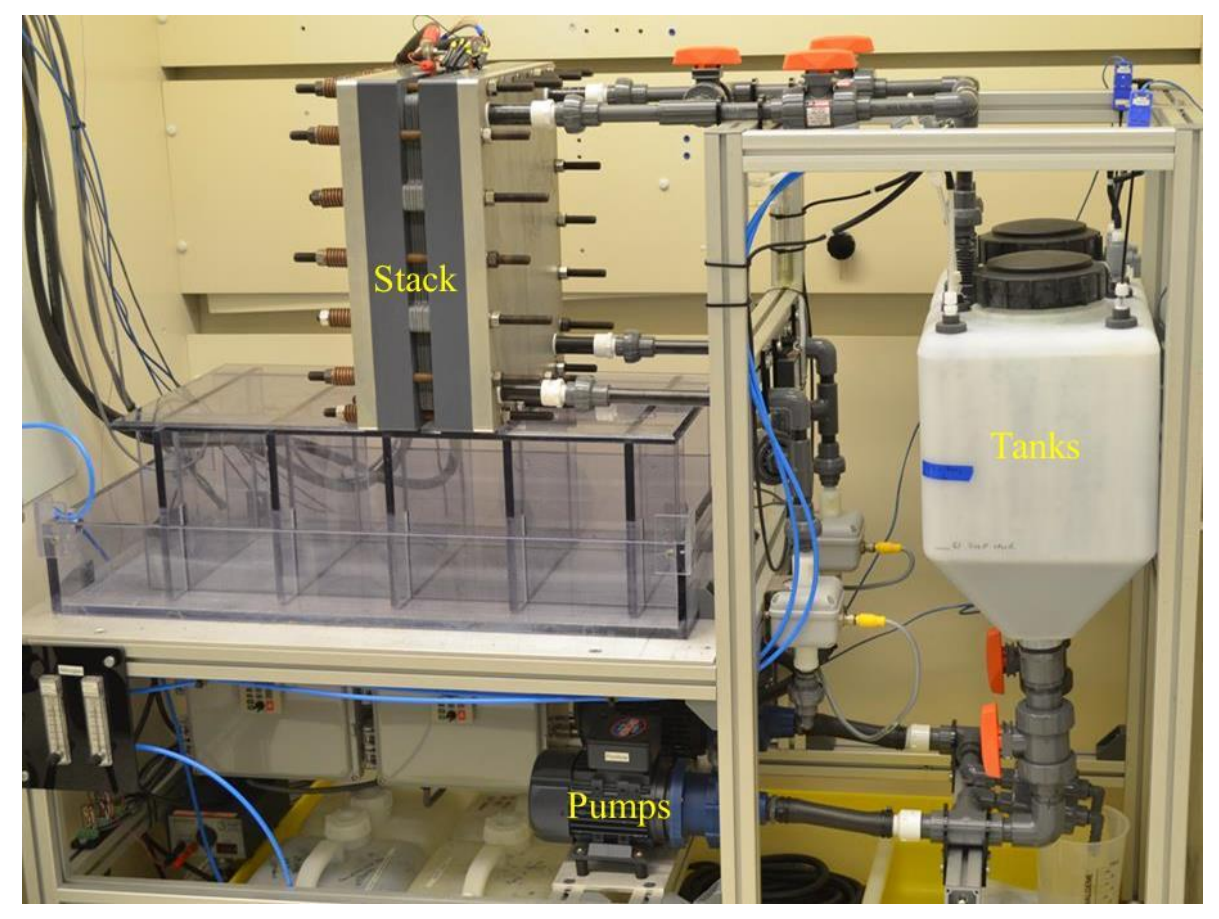

Figure 2. 

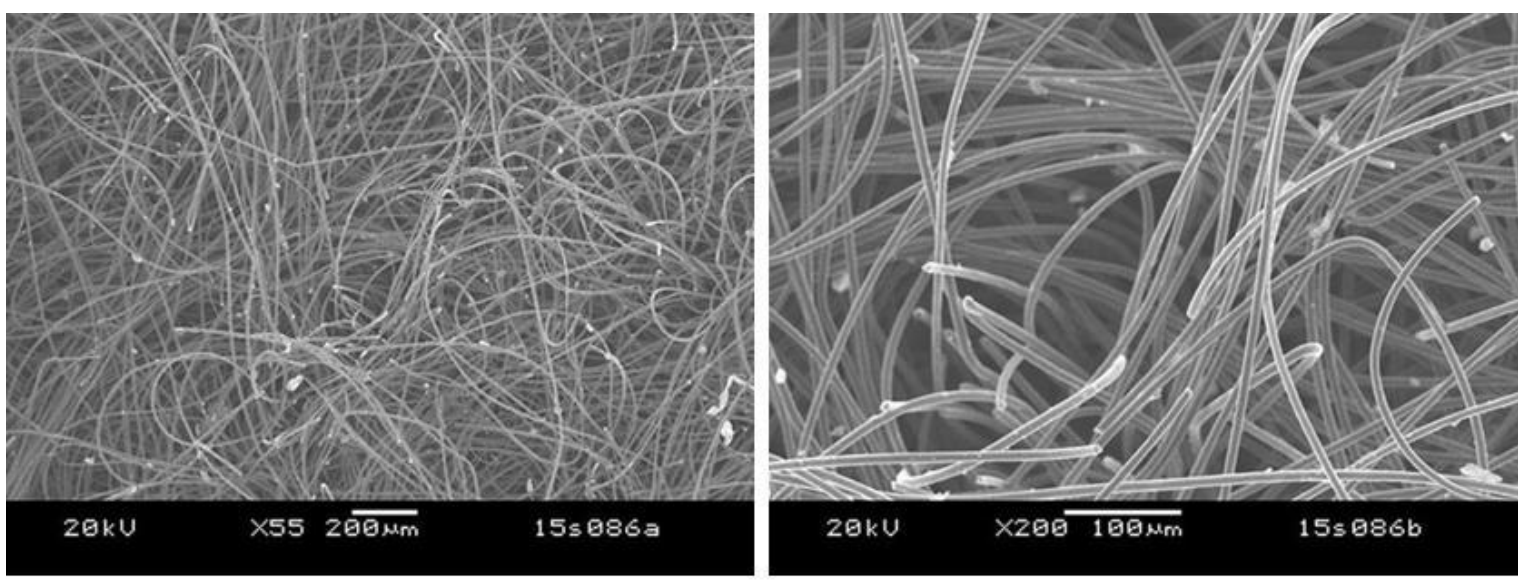

a.
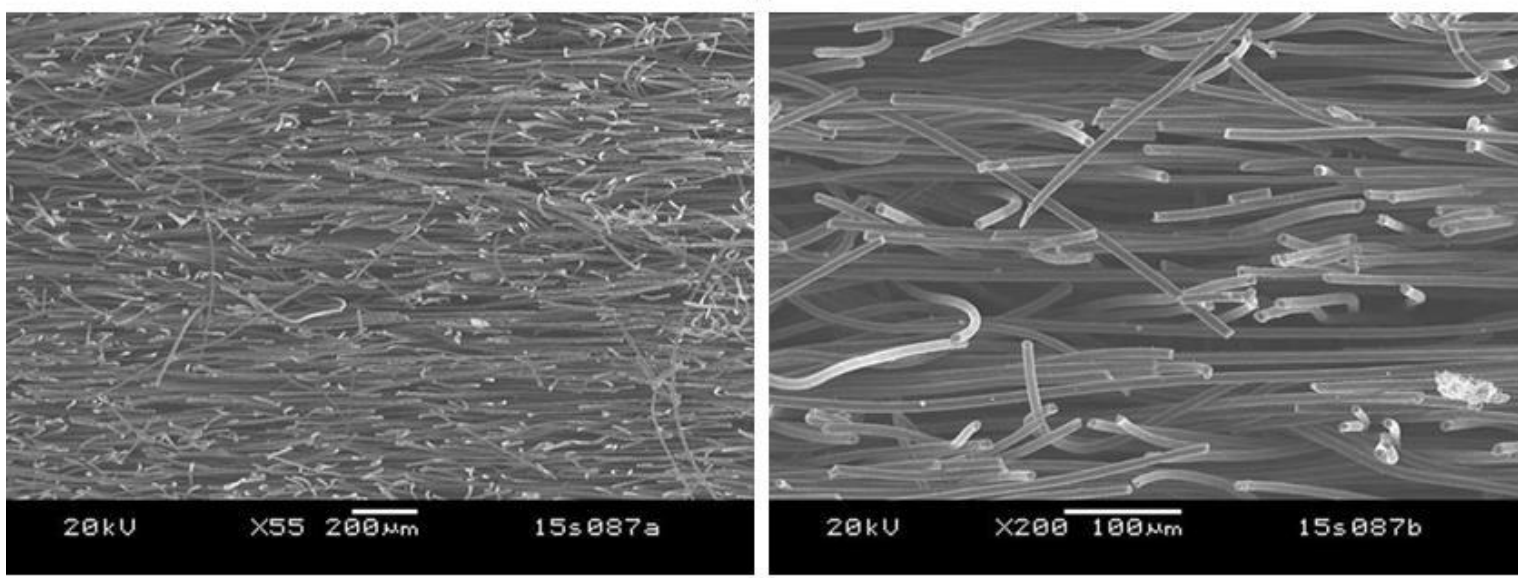

b.

Figure 3. 


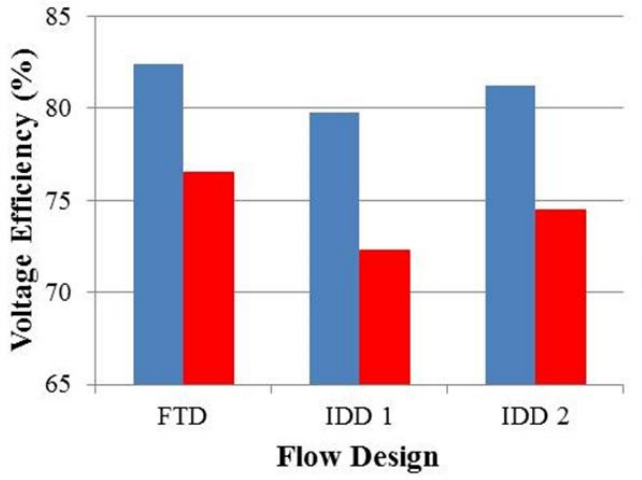

a.

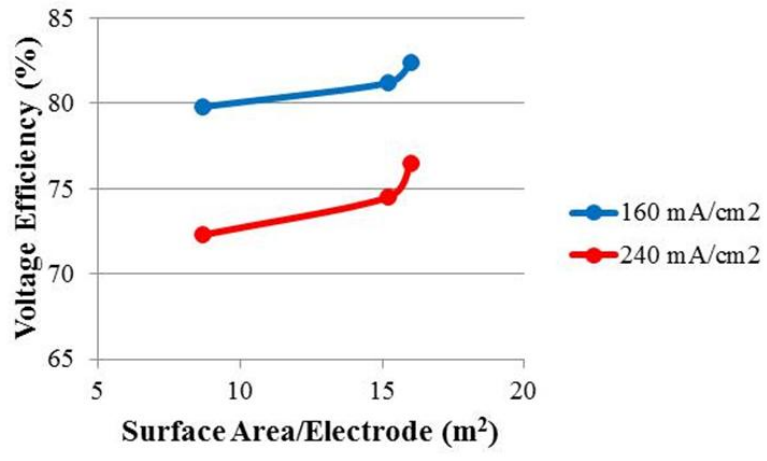

c.

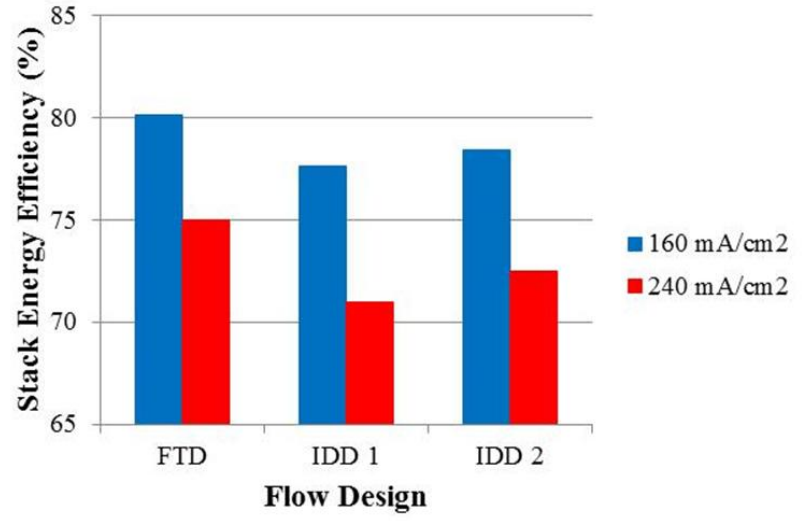

b.

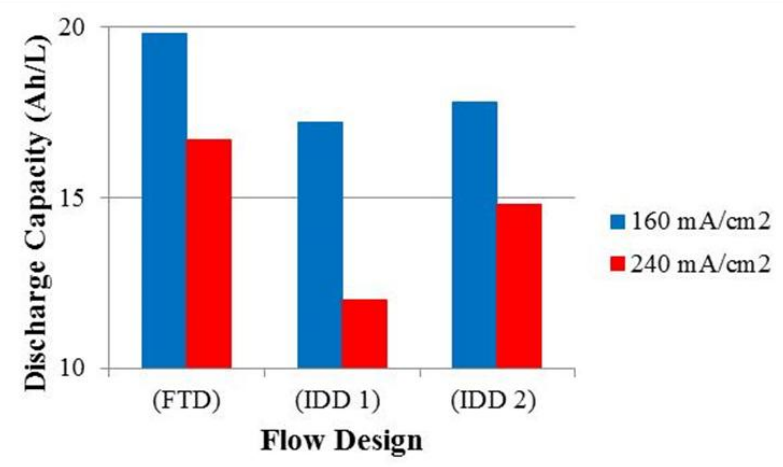

d.

Figure 4. 


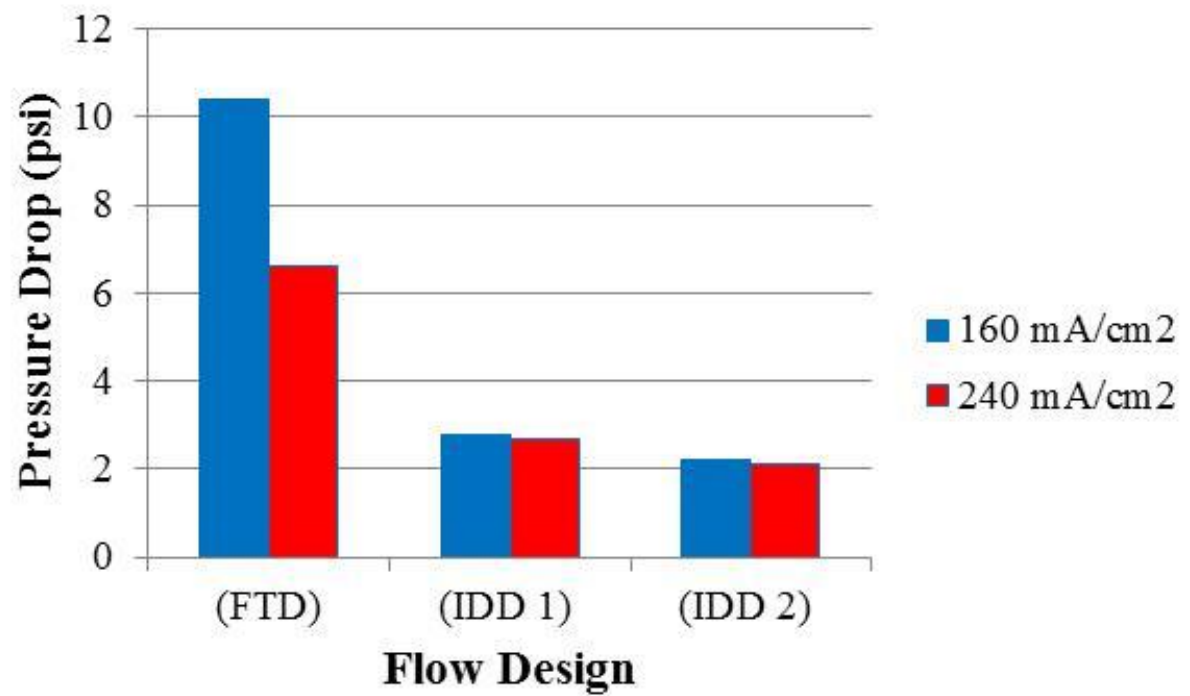

Figure 5. 


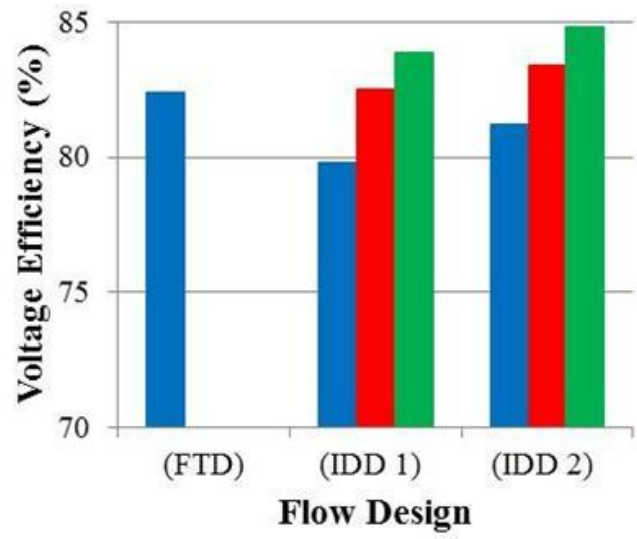

a.

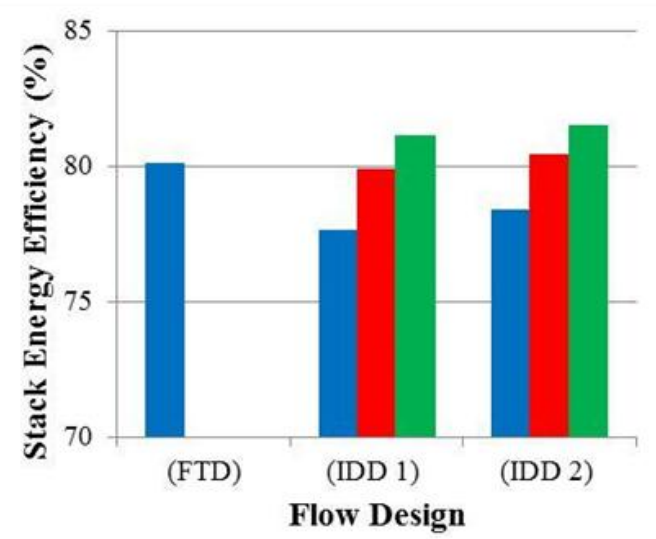

c.

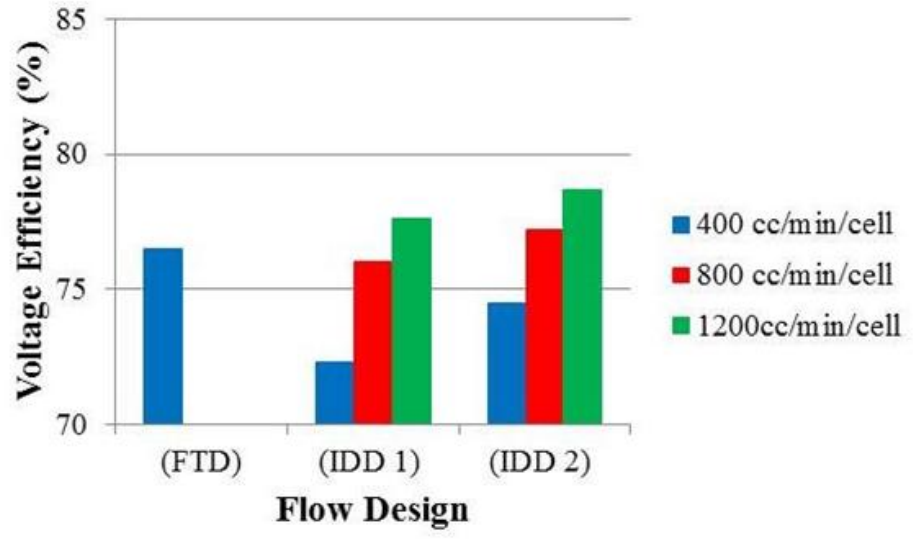

b.

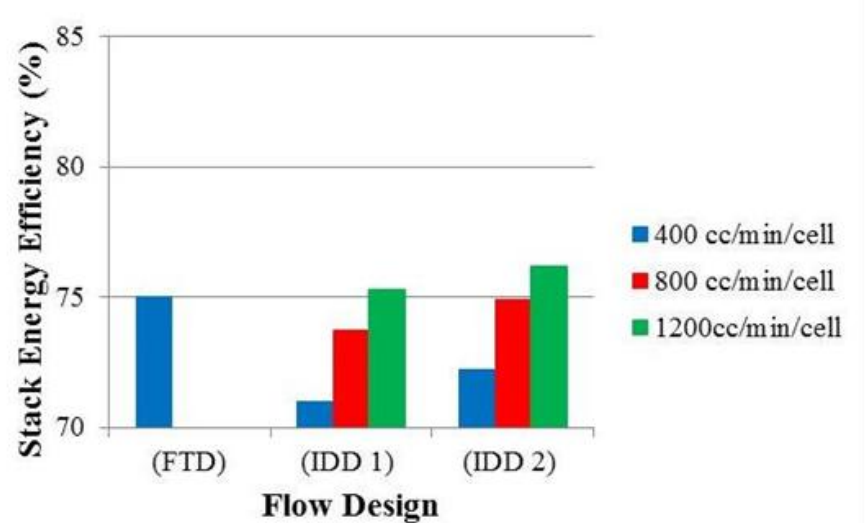

d.

Figure 6. 


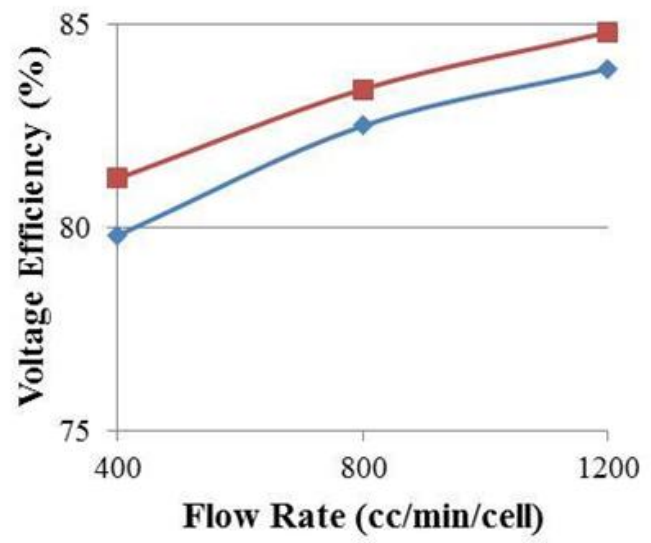

a.

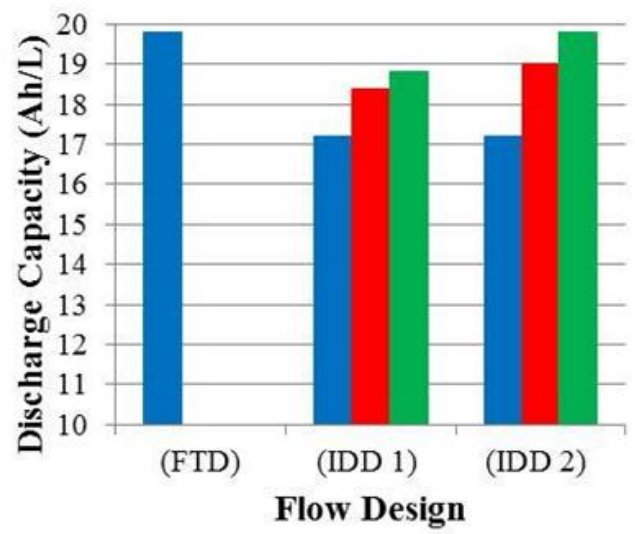

c.

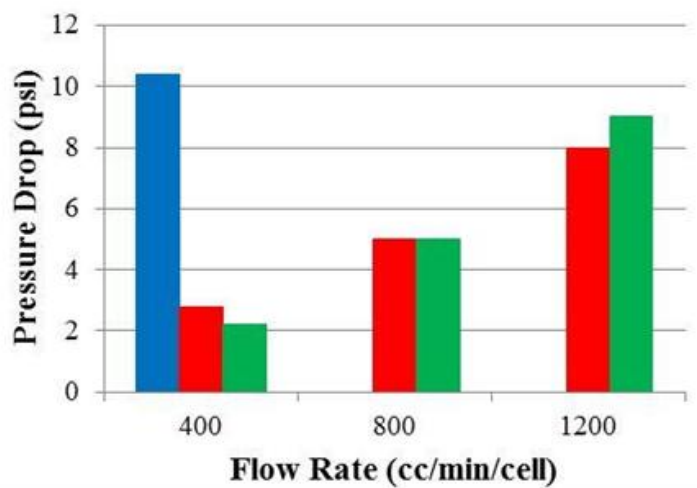

e.

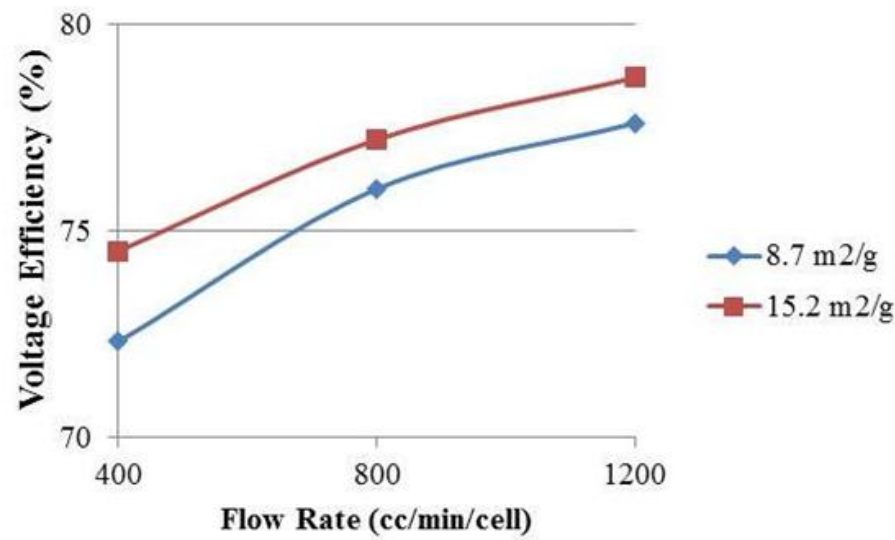

b.

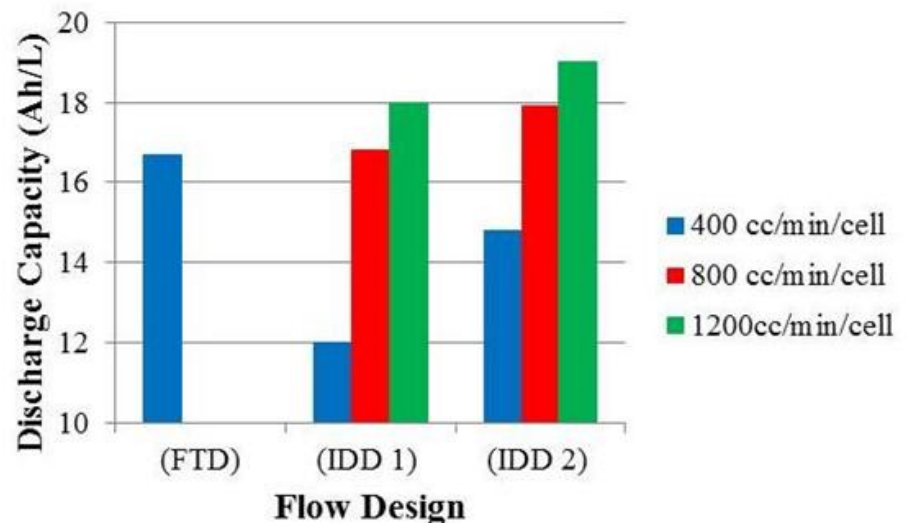

d.

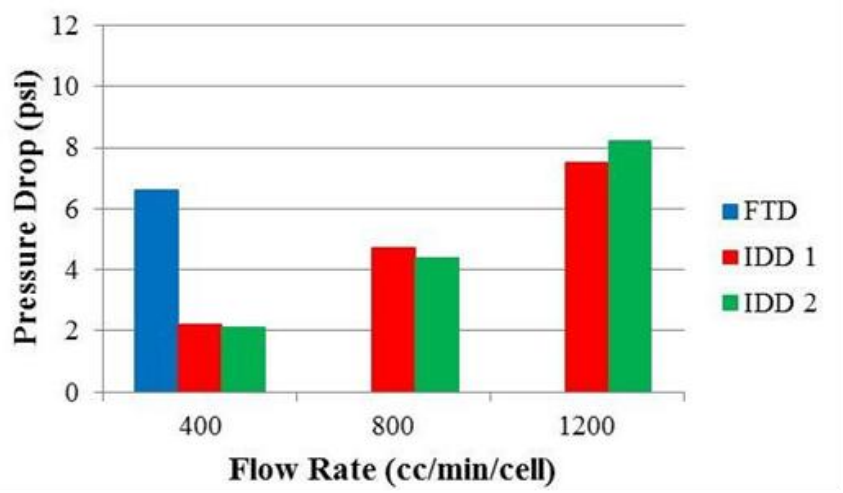

$f$.

Figure 7. 


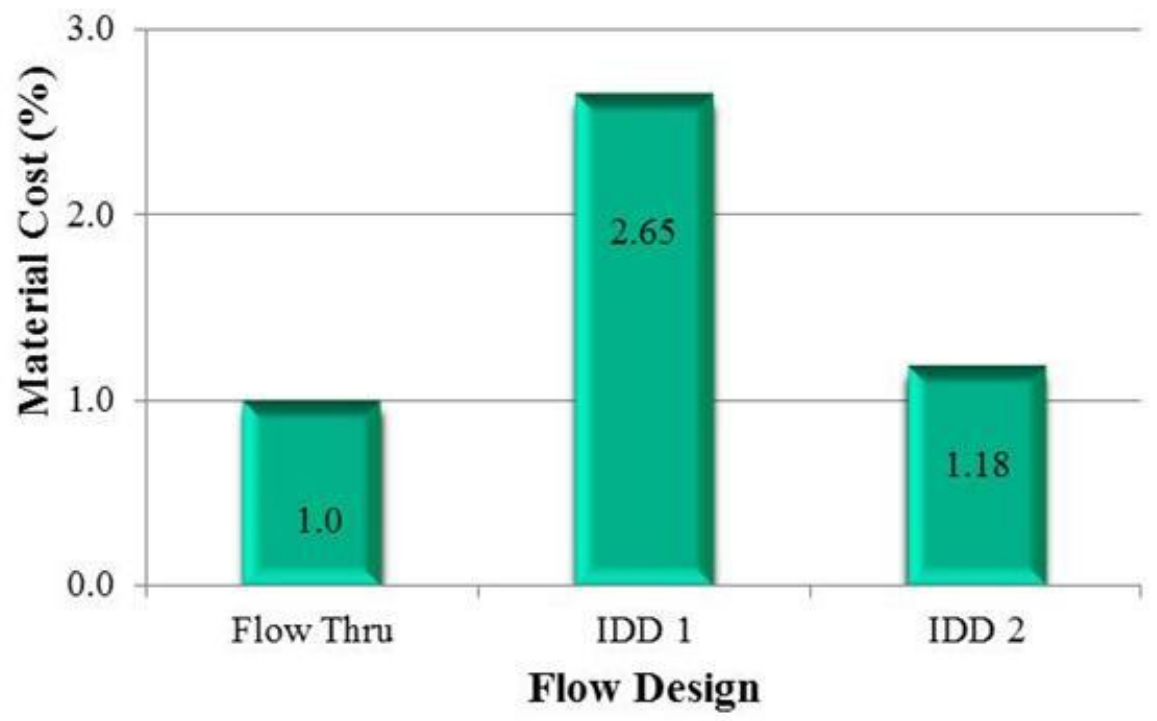

Figure 8. 